\title{
PENSANDO SOBRE A CIDADE CONTEMPORÂNEA
}

\author{
MARIA CECÍLIA NOGUEIRA LINARDI ${ }^{1}$
}

LINARDI, M.C.N. Pensando sobre a cidade contemporânea.Semina: Ci. Soc./Hum., Londrina, v. 15, n. 3 , p. 239-245, set. 1994 .

RESUMO: Propomos identificar alguns tópicos para a compreensão da cidade contemporânea. Através das noçóes de tempo, velocidade, obsolescência de lugares e coisas, inovações da ciência e tecnologia, buscamos contribuir para uma redefinição das relações sociomespaciais presentes na cidade atual. Em termos metodologicos, enfatizamos a importância do conhecimento histórico enquanto ponto de partida, que nada mais é do que o próprio conhecimento da realidade. Acreditamos ainda que este pro cedimento possa permitir a renovação da teoria. Observamos então que a modemidade aiual apresenta enquanto caracteristica, não apenas a intensa prolíeração de objetos, a abundância, mas também é marcada pela rapidez em que são processados, assim como pela sofisticação tecnológica em que produzidos. Enim, buscamos observar como a velocidade e os novos ritmos caracterizam a presente transformação do ambiente urbano, o qual tende a tomar-se obsoleto, cada vez mais, em menor intervalo de tempo.

PALAVPAS-CHAVE: Cidade contemporânea, Tempo, Velocidade, Obsolescência, Modernidade atual.

\section{INTRODUCGA}

Acreditamos que somente a clara compreensão da realidade, poderá então permitir, tanto ao individuo quanto coletivamente, uma projeção da forma de sociedade que melhor corresponda a seus anseios. Acredita. mos aînda que, somente acontecerå tal compreensão do presente, se estiver garantida uma discussão e entendimento das possibilidades e tendências do desenvolvi. mento futuro, tanto das relaços sociais quanto do espa. ş.

Neste senido, confimamos a importancie do trobaho intelectul, enquaro forme de chegarmes a une avaliaç desta realdade, por sep tambern um instr. menty de avaliaça antecipaçän de shuaços futuras.

É dentro desta visato que apresentamos este trabeTho buscando alguns tópicos que possam contibuir ao entendimento tanto da organizaçăo do territôrio tal $60-$ mo da própria sociedade. hole. Acreditamos então eçar cumprindo com nossa função de profíssionais do ensino e pesquisadores, devolvendo à mesma sociedade, donde alimentamos nossas especulaçőes, um relato enquanto explicação e mesmo alerta acerca dos fatos estudados. Assumimos assim o compromisso de compreensão da realidade, colaborando de alguma forma no sentido de romper o envólucro que mascara a compreensão dos fatos e da sociedade.

Apresentamos ainda enquanto preocupação central neste artigo, o enfoque metodológico e conceitual sobre o tema abordado; partimos de uma definição acerca da cidade contemporânea, hoje.

\section{\%. À GUISA DE DEFINIÇÄO DA CIDADE CONTEMPORANEA}

Pretendemos identificar alguns tópicos pertinentes ao entendimento da cidade contemporânea. Dessa maneira, atraves das noçoses de tempo, de velocidade, da obsolescencia de huares a coisas, das inovaçōes na ciên. cia e tecnologia entim, abordamos diferentes niveis qua parecom contribuir para uma rederinicăo das relaçōes só. cigmespaciais presente na cidade hole.

Primeiramenta, desiacamos a impontancia de ado ora. mos enquanto ponso de partica o conhecimento histor:. 60 aqui considerado enquanto apreensão da propria rea. lidade: acreditamos ainda ser este o mecanismo que pode conduzir à renovação da própria teoria. Enfatizamos as sim, a importância de estarmos atentos ă prốpria realidade, buscando em suas múltiplas relaçōes, explicaçöes $\theta$ justificativas, como afirma SANTOS (1982, p. 132):

"É preciso ir recolher no real, o que ele é, peça por peça, mecanismo por mecanismo, ilação por ilação, e desse conjunto de coisas e das relações que as animam, examinando à luz de conjuntos maiores, extrair significações, que, sendo

1 - Departamento de Arquitetura e Urbanismo/CTU - Universidade Estadual de Londrina, Caixa Postal 6001, Londrina, PR, Brasil, CEP 86051-970. 
particulares ao caso estudado, tragam igualmente, ainda que escondida em seu bojo, a dimensão universal, e encerrem um germe ou uma promessa de abstração factualmente construi$d a "$.

Quando buscamos a compreensão e a avaliação de algum aspecto da realidade, fica também implícito a preocupação da análise do contexto onde se encontra inserido este fragmento; parece ser este procedimento um requisito básico àqueles que pretendem uma compreensão da realidade.

Neste sentido, ao abordarmos a questão da cidade contemporânea partimos de uma avaliação da abrangência da modernidade atual. Vale esclarecer ainda que, buscamos entender também questões que transcendem o âmbito da aparência, enquanto possibilidade de aden. trarmos à compreensão do significado. Mediante este procedimento, acreditamos ser possivel uma reflexäo acerca da produção espacial, num determinado momento histórico.

\section{CARACTERIZACÄO DO MOMENTO ATUAL}

No inicio do se̊culo, a modernidade entra em cena e se manifesta de forma intensa na cidade, transformandoa, fazendo nesta ser instaurada a metrópole, segundo mủltiplas e diversas formas; a cidade abre passagem para metrópole, e irrompem ả cena as multidöes. No final do sëculo $X X$, vivemos um momento de intensa renovação de fatos e dos objetos, onde de forma declarada superamos a experiência da modernidade deflagrada pelo in. dustrialismo, para adotarmos nova concepção, que gestada desde então, foi particularmente definida lou mes mo transformada) com a revolução cientifico técnica, após a Segunda Guerra, (SANTOS, 1985). Contudo $8 \mathrm{im}$ portante frisar que esse "novo" surge e convive com formas jå existentes, permitindo estabelecer um meca. nismo dinâmico onde coexistem, e por que não, se en trelaçam de forma peculiar, a tradição e a inovação.

Desta forma, buscamos analisar neste periodo, marcado pela renovação intensa, caracteristicas a peculiaridades presentes na esfera da produção e do consu. mo, possibilitando assim traçar mediante tais evidências o perfil da modernidade atual.

Vivemos hoje um perlodo onde a renovação inten. sa, traz consigo a marca da passagem; estigmatizados pelo sentido e situaçăo onde prefixo "pós" tende a se instaurar de forma genérica. Sendo assim adotado, permite insinuar que estamos num estăgio posterior a uma dada época, distantes de um passado que embora re. cente , hoje se encontra transformado. Estaremos hoje vivendo a Pos-modernidade?

Neste ponto, concordamos com HABERMAS (1987, p. 115), quando aponta a transição enquanto particularidade atual ${ }_{z}$ sendo de forma genérica empregado o termo "poss";

"com este soós' querem os protagonistas se

Semina Ci. Soc $d$ Hum, v. 15, n. 3, p. 239-245 desfazer de um passado; a atualidade não podem ainda dar um novo nome, na medida em que para os reconheciveis problemas do futuro não femos ate agora nenhuma resposta. Fórmulas como "pós-ilustração" ou "pós-história" desempenham o mesmo papel. Gestos de despedida apressada como estes são adequados aos periodos de transição.

As evidências sugerem estarmos num periodo caracterizado pela crise, que nada mais é do que a transição entre uma situação que mostra já estar superada, e um novo perfodo que ainda não se encontra delineado.

Vivemos um momento de extensa multiplicação da produção e fluidez dos objetos construidos no espaço, permitindo cada vez maior acesso a esses, assim como acelerando a obsolescência das coisas produzidas. Vive. mos igualmente a inauguração da era do happening e do descartável, em relação aos lugares, as manifestaçöes culturais, aos valores e objetos produzidos, pois observamos freqüentemente transformaçóes intensas ocorrendo em intervalos de tempo cada vez mais reduzidos. Segundo DORFLES (1965, p. 221), podemos observar tal transitoriedade no próprio cotidiano, pois

"novos ediffios acabados de construir para avistar junto deles outros jå om vis de demoliça: basta considerar a variabilidade da moda lentinna, das modas arísticas, iterárias, poéticas. "

Podemos ainda afirmar que este ritmo de inovaçōes estă perfeîamente adequado às necessidades da so. ciedade atual que traz em seu interior a marca da socie. dade de consumo.

Voltamos a atençäo para a vasta oferia e prohifers. ção de objetos, assim como a intensa renovação dos tă tos: isto parece tecer o centro da sociedade contempera. nea, como anrma BAUDRILLARD $(1976,0.15)$.

\begin{abstract}
"A nossa volla, existe hoje uma espécie de evidencia fantastica do consumo $\theta$ da abundancia, criada pela muliplicaçăo dos objetos, dos serviços, dos bens materiais, originando como que uma calegonia mundial de mutação fundamental na ecologia da especie humana. Para lalar com propriedade, os homens da opulencia não se en. contram rodeados, como sempre aconecera. por outros homens, mas por objetos."
\end{abstract}

Entretanto não \& caracteristico do momento arual apenas a intensa proliferação dos objetos, sua abundân. cia, mas sobretudo $\&$ importante frisar, a rapidez em que são processados, tal como a sofísticação técnica em que såo produzidos: o ritmo e velocidade, parecem ser um aspecto particular, e também fundamental neste periodo. Tanto ao nivel das idéias, quanto dos objetos construl dos, as mudanças se processam num ritmo intenso, o que também parece implicar numa renovação tambe̊m inusitada no modo de vida ${ }_{8}$ e nas relaçöes entre os indiy. 
duos. Esta situação tendencialmente irá trazer uma intensa fluidez de novos elementos pelo espaço, que por outro lado pode ainda significar maior possibilidade de acesso, à todos, a estes bens.

Podemos apontar neste sentido efeito e o significado da produção em série: se por um lado, está associada a pesquisa tecnológica, e vinculada a mundialização das idéias, dos valores, dos costumes, por outro, pela possibilidade de sua abundância tende também favorecer a obsolescência precoce dos objetos e fatos: hoje tem maior sentido o descartável, do que o permanente. A idéia de consumo rápido, do transitório tem mais impacto do que o eterno. Podemos encontrar também no ambiente urbano, as marcas e indícios desta abundância e perecividade: a profusão dos objetos, de idéias e de informações, comprovam a todo instante a presença do temporário. Concordamos com a afirmação de BAU. DRILLARD (1976, p. 16) acerca da produçăo intensa dos objetos nas sociedades de consumo, pois

"O amontoamento, profusão revela-se evidentemente como traço descritivo mais evidente. Os grandes armazêns, com a exuberáncia de conservas, vestidos, bem alimenticios a de confecção constituem como que a paisagem primária $e$ o lugar geométrico da abundância." "No "No amontoamento, hå mais que a soma dos produtos: a evidência do excedente, a negação mágica e delinitiva da rareza, a presunção materna, a presunção matema e luxuosa da terra da promissäo."

É importante irisar, que em meio a esta profusão de objeto, de informações, hă uma constante que deter mina a essência de um periodo, que é a necessidade de consumir: como afirma DORFLES (1965, p. 221),
"abonsumir, como consumir-se: 0 consumo - Uturo entendido transitivamente no sentido de consumir algo, de se servir, não sơ de alimenios, mas ambém da cultura, da arte, da ciência, de maneira quase 'comestivel', como entendico in iransitivamente no sentido do 'consumirase, do desgastaruse, do estar sujeiro à entropia e a ob- solescência, de um deierminado ienömeno - sem divida uma das consiantes basilares da FOOSSE Cra

Mesmo considerando que em outras perodos hisroricos estuaram presente a obsclesc8ncis, ramo da pro. dutos quanto de idsias, implicando numa constante recio dagem, ou mesmo am consumir mai do que o necss. Tio para a sobrevivencia, que tambèm é forma de desperi. dicio e delapidaçäo dos meios do ambiente, o momento atual tem sua marca própria: podemos defin wo mediante a presença do fiom acontecimentos säo concobidos para durar pouco muito pouco; a sociedade de consuno traz em sevinterior a neSeminatia Cis \$ocd Hurna, v, 15, no, 3, p. 239-245 cessidade de uma ordem passageira ou ainda como define BAUDRILLARD $(1976$, p. 56), onde os objetos são produzidos não em função do seu valor, mas em função da sua morte."

"O que hoje se produz năo se fabrica em função do respectivo valor de uso ou da possivel duração, mas antes em função da sua morte, cuja aceleração só é igualada pela inflaçăo dos preços."

Vale ainda acrescentar que esta renovação acelerada dos objetos e dos fatos, é facilmente aceita pela sociedade, a qual não oferece resistência: muitas vezes a própria publicidade, em forma de discurso em defesa do consumo, tende a enfatizar a necessidade de sujeitar-se ao valor/moda, em nome (ou mesmo caricatura) do progresso.

Realmente, esta nova configuração tende apresentar-se em vários territórios: nesta, igualmente nova sociedade, observamos uma tendência a manifestação de formas de consumo e de produção caracterizadas pela rápida renovação. Esta possibilidade parece ter contribuído não só em relação ao maior fluxo de trocas entre os diferentes territórios produzem, mas sobretudo pelo que são forçadas a consumir . Contudo estas transforma. çóes näo acontecem apenas no âmbito do que é produzido e do que é consumido, mas também na própria paisagem, na linguagem e no significado do espaço, no di. mensionamento do tempo e nas relações sociais. A pre. senç marcante desta necessidade de mudança ${ }^{\circ}$ de transtomaçōes da base existente neste novo periodo, tendencialmente faz com que qualquer pedaço do terrisorio esteja sujeito às determinações até certo ponto co-

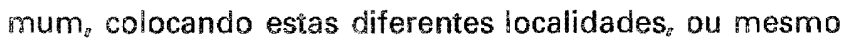
naçőes, sob o mesmo nexo da modernidade: isto tem mportância relevante, pois a simultaneidade dos fatos fol cepaz de redefinir tanto o espaço, quanto o tempo, em diferentes pontos do território, como adverte SANTOS (1988, p. 59):

\footnotetext{
"Nazo hå pals, nem que seja um ponto minimo, que deixe de estar ligado a essa modernidade global; e nesse novo subsistema hegemônico, a lei do lucro se iransforma na lei internacional do Lucro $_{2}$ passa a ser o motor ínico do movimento do mundo".
}

Partindo destas consideraçeres acerca da sociedade contemporânea d da repercussäo da nodemidado aubl. 6 que pretendemos antender a redefmica da cidade neste contexto: parece gue as condiços urbanas, om particular tratando das grandes cidades, revelam uma 10 gica, una ordem onde os principios norteadores rovalam as colocaçós iniciais. Entendemos que as cidades, hoje. tendem a serem consumidas fireralmente, onde muito fo. cimente tudo colocado abaixo sendo esta base oxistente parcial ou coralmente renovada para que seja pos. sivel finamente termos algo "secessariamente" nove 6 
inusitado, que traz em seu bojo o estigma sempre presente, do temporário e passageiro. A destruição parece ser algo vital para a sociedade de consumo, como afirma BAUDRILLARD (1976, p. 58):

\begin{abstract}
"a sociedade de consumo precisa dos seus objetos para existir e sente necessidade de os destruir. $O$ "uso" dos objetos conduz apenas ao seu desgaste lento. $O$ valor criado reveste-se de maior intensidade no desperdício violento. Por tal motivo, a destruição permanece como alternativa fundamental da produção: o consumo não passa de termo intermediário entre as duas. No consumo, existe a tendéncia profunda para se ultrapassar, para se transfigurar na destruição. Só assim adquire sentido."
\end{abstract}

Dentro da sociedade pós-industrial, a destruição aparece como uma condicionante necessária e natural, como uma decorrência esperada e aceita, muitas vezes em função da possibilidade da própria abundância. Além disto, esta renovação crescente das necessidades, impulsionando a proliferação dos objetos e a produção em massa, trazendo em seu interior ralzes cravadas não mais em bases estritamente locais, mas sim globalizante.

Paralelamente podemos acrescentar as circunstâncias e a forma como os homens se relacionam, entre si e com o ambiente onde se encontram; esta avaliação acerca das formas de trabalho tendem a trazer mais informaçōes sobre o cotidiano em nossa sociedade atual, e conseqüentemente sobre o próprio fato urbano. Apontamos então para as mudanças ocorridas ao longo do tempo, entre a esfera pública e privada, em relação ao espaço do trabalho: estes dois niveis tendem a definir o próprio espaço, tanto no âmbito formal quanto em seu significado. Concordamos com PROST (1992, p. 21), quando afirma que no século $X X$ ocorre uma redefinição entre as esferas do público e privado, pois foi a partir de entäo que o tra. balho tende a sair da esfera doméstica e migrar para a esfera pública. Progressivamente os locais de trabalho deixam de sobrepor a esfera doméstica: mas não se trata apenas de uma diferenciação dos espaços ${ }_{z}$ e sim estamos vivendo um perfodo em que as novas condições de trabalho carecem de uma nova disciplina, garantida me diante estabelecimento de normas especificas, de caráter não mais individual, mas tipicamente coletivo.

Mediante estas novas formas de trabalho, viabilizados pelo novo estágio de desenvolvimento da ciência da técnica, foi possivel (e igualmente necessário) a produção de espaços cada vez mais bem definidos quanto a sua especialização, assim como apresentando fronteiras claramente definidas.

Acreditamos que esta passagem para espaço público da atividade de trabalho, permita tecer mais uma caracterlstica da cidade contemporânea. A dissociação entre o local de moradia e o local de trabalho, tende impor cotidianamente longos trajetos pela cidade, dentro de uma disciplina pensada para a coletividade, onde o máximo rendimento $\&$ a regra geral. Parece que tanto a nova for-

Semina Ci. Soc/Hum., v. 15, n. 3, p. 239-245 ma de ordem espacial, quanto a nova forma de vivência cotidiana, encontram-se diretamente relacionada, e também subordinadas, às determinações da disciplina e da vigilância. Os contatos mútuos diminuíram, tal como os encontros; como afirma PROST (1992, p. 123), o que governa o cotidiano das pessoas é o ritmo impessoal da produção, assim como "o urbanismo moderno trata a circulaçāo como um fluxo. O deslocar-se portanto, exclui o encontro e a eficácia exclui o perambular".

A própria presença e influência dos meios de comunicação de massa trouxeram diversas inovações, tanto na esfera privada quanto na esfera do trabalho: o rádio, a imprensa, as diferentes formas da publicidade, a televisão e toda a informática permitiram trazer para a esfera privada parte do que estava acontecendo fora, garantindo a propagação de novas formas de consumo. Isto foi muito significativo também, para comparar e incorporar diferentes situações, diminuindo as diferenças entre diferentes territórios e entre diferentes regiōes, sendo então possivel que a vida privada se redefina mediante esta invasão por novos valores desta época marcada pelo consumo.

Consideramos que a forma como cidade contemporânea está estruturada, pressupõe uma relação com os objetos de consumo existentes, mediatizada pela publicidade e pelo discurso da "necessidade" do progresso. Cotidianamente assistimos a destruição de espaços e regras, que se tornaram obsoletos. Agora a cidade e o local das novidades, de um arsenal de imagens e representações que tendem a estabelecer e definir para outras localidades, uma possibilidade de busca e realização.

A necessidade do controle do tempo, da remuneração e da produtividade, definem uma nova disciplina, limites, fiscalização e a necessidade da complementariedade entre atividades, tende a estabelecer um novo panorama para tanto paras as relações entre os homens na esfera da produção, quanto em relação ao espaço que as sustenta.

\section{ALGUNS TÓPICOS PARA AVALIAR A MODERNIDADE ATUAL}

Consideramos que as inovaçöes da ciência e tec. nologia não surgem ao mesmo tempo e de modo a substituir por completo a base preexistente, mas sim de forma gradativa, conforme as características de cada formação social em questão. Enfatizamos então, ser fundamental para interpretar as características de um determinado momento histórico, a noçäo de tempo. Neste sentido, ao partirmos deste enfoque fica também implícito a importância de refletirmos acerca da própria velocidade; esta por sua vez, tende a definir e redefinir distâncias no espaço e novas relações temporais, e por assim dizer, permite ainda uma redefinição em relação ao próprio cotidiano. Embora tal aspecto seja particularmente observado nas grandes cidades, não podemos afirmar que estas representem o local/origem da velocidade. Ao contrário, as relações de poder em qualquer época, assim como o 
exercício da hegemonia, das conquistas enfim, estão ligadas diretamente à velocidade, como aborda VIRILLIO (1983, p. 49).

A nova utilização do tempo tem provocado uma renovação não apenas no âmbito das relações sociais, mas também espaciais: o espaço de forma geral tende a apresentar menor Indice de barreiras, apresentando assim maior fluidez no meio ambiente. Neste novo contorno, onde a produção de informação e dos objetos podem ser propagadas de modo intenso pelo território, o que mais. conta são os interesses que estão por traz desta ordem; esta nova situação também parece preencher uma das necessidades vitais da manutenção do poder.

Atualmente, sobremaneira nas grandes cidades, podemos afirmar que além de local de moradia, de permanência de pessoas e coisas, também nelas se concentram, ao mesmo tempo em que se renovam, de forma particular o trânsito de idéias, acontecimentos e serviços. Podemos concluir que as condições modernas, permitem extravasar os limites locais; como adverte BERMAN (1986, p. 15), pois a experiência a mbiental da modernidade tende a anular as fronteiras geográfica e racial, unindo de alguma forma a espécie humana. Isto não implica na existência de uma situação de igualdade entre os diferentes povos; existe uma certa ambigüidade, onde ao mesmo tempo que une também separa, sendo fundamental à gestão desta ordem, o comando que tende a ser cada vez mais abrangente.

Fica de certa forma evidente que o mundo se transformou, na medida em que o próprio capital se distribui também de forma renovada: os palses em desenvolvimento procuram constantemente grandes empréstimos dos bancos e dos grupos internacionais. Ainda, submetidos ao processo de globalização, os objetos produzidos em um determinado território, poderão ser consumidos ou concorrer com outros paises. Fica ainda a mesma possibilidade, em relação as diferentes regiões dentro do mesmo território.

Entretanto podemos observar o avesso da aventura tecnológica, materializado na própria obsolescência dos objetos produzidos Estas novas condições, ao serem incorporadas ao cotidiano das pessoas, provocam novas relações entre espaço e tempo, tanto individual quanto coletivamente, estabelecendo então não apenas uma nova forma, como também um novo conteúdo ao espaço produzido.

\section{CONCLUINDO SOBRE A CIDADE CONTEMPORÃNEA}

Nas grandes cidades em especial, o impacto deste novo perlodo provocou crescimento e transformações desmesuradas. Em todos os cantos do território, de alguma forma foi possivel experimentar a intensa ação renovadora decorrente da ciência e da tecnologia, representada pelas manifestações de novas velocidades, novo uso de tempo, pela obsolescência de objetos e dos fatos, entre outras.

Vários aspectos podemos descrever, tentando evi- denciar a amplitude das transformações decorrentes da modernidade atual; de forma geral, novos ambientes foram criados, ao mesmo tempo em que se torna ainda mais contrastante resquicios de outros momentos: sendo característica a unificação das formas de consumo e de produção, também vale apontar para o surgimento das formas de luta de classe e de reivindicação social, que se aglutinam: as cidades crescem, e novos equipamentos e necessidades se impõem, assim como novas formas de comunicação e de informação; as grandes cidades são marcadas não apenas por uma verdadeira explosão demográfica, mas também intrincada união dos opostos, ou seja a presença da diversidade mediante a constatação da coexistência entre o moderno e o tradicional. Enfim, hoje vivemos a possibilidade de contato físico, ou mesmo ao nivel das idéias, entre diferentes formas de consumo e produção, particulares às diferentes sociedades. A grande característica, e por assim dizer a ambigüidade presente no momento atual, reside justamente neste ponto: a fantástica diversidade decorrente do avanço tecnológico, onde os opostos podem conviver de forma inter-relacionada. Podemos concluir que, a mundialização das idéias e dos costumes, dos valores, progressivamente pode contribuir para diminuir as diferenças ou mesmo particularidade das diversas culturas.

Enfim, a grande novidade do periodo atual reside no sentido da generalização e abrangência das inovaçōes, possivel mediante a revolução técnico-científica. Mesmo existindo este novo ritmo, que de certa forma é imposto a sociedade, não podemos esperar que haja um só tempo e compasso para todos; determinadas localidades, ou mesmo atividades, sofrem alterações em menores intervalos de tempo do que outras. Mas em todos os casos como já afirmamos, encontramos a coexistência entre o que há de mais inovador e resquícios de outros momentos. Entendemos que as inovações da ciência e da tecnologia, não surgem da mesma forma e em diferentes 10 .

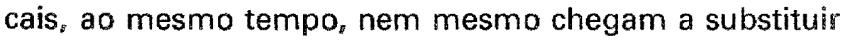
por completo a base pré existente, mas sim, de forma gradativa a nova situação tende a ser ajustada dentro das particularidades de cada formaçăo social, ao mesmo tempo que tambêm trazem no seu interior, uma força renovadora e até mesmo revolucionária. Sendo estas transformaçōes, parciais e de forma gradativa $a_{s}$ é possivel ocorrer a coexistência entre o tradicional e o moderno, tanto ao nivel do território quanto das relações sociais.

Contudo a produção social e as transformações não acontecem ao acaso, mas determinadas por uma ordem estrutural. Podemos então garantir possibilidade de identificar dentro da história periodos, onde estas mudanças se manifestaram enquanto crise ou mesmo ruptura. Neste sentido, o entendimento acerca da modernidade tem aqui o sentido de também permitir identificar na produção social, este novo momento.

Em sua formação, a cidade contemporânea apresenta-se enquanto resultado da junção de muitas partes, que mesmo sendo similares trazem em seu conjunto algo desconexo. De forma diferente, na cidade antiga poderlamos até mesmo identificar diferentes partes, mas exis- 
tia igualmente uma totalidade coesa; tendendo a ser sempre reconhecivel, inconfundivel. No entanto, a cidade contemporânea tem como sua marca a semelhança, sendo o difficil, identificar a qual pais ela pertence, pelo menos a primeira vista.

Se a velocidade da produção e renovação tende a exigir uma flexibilidade nas organizaçōes sócio-espaciais, em função do constante processo de transformação dos espaços, também fica impllcito algo que fundamentalmente permite diferir de perlodos precedentes: estamos exatamente apontando para a nova relação espaço-tempo, onde a sociedade como um todo tende a ser comandada por velocidades e ritmos globalizantes.

Os grandes aglomerados urbanos, em especial as metrópoles, tendem a expressar importante papel enquanto centro de desenvolvimento e gestão desta nova forma de produção do conhecimento cientifizado, assim como na produção e propagação das informações. Refletindo sobre o caso brasileiro, parece que é na metrópole, e particularmente em São Paulo que podemos observar essas novas formas de produção e gestão das informaçōes: a partir deste centro, que expressa historicamente certa hegemonia no território nacional, notamos a propagação destas inovações. Contudo, se por um lado podemos afirmar que no território nacional a região Sudeste, representa uma concentração de recursos e da produção, por outro, também vale dizer que ocorre uma dispersão, podendo ainda ser compreendida enquanto 'pedaços' da metrópole, fragmentados pelo espaço. Este enfoque parece ser importante para a identificação de uma hierarquia entre os nủcleos decisórios da produção, também entendida enquanto uma articulação entre o tradicional e o moderno, numa esfera nacional, favorecidas neste novo momento pela intensa fluidez de informações e objetos. Ao mesmo tempo em que se tornava possivel e necessário uma descentralizaçäo das aglomerações, igualmente importante se tornava uma redefinição da divisão regional e internacional do trabalho, passando necessariamente por uma especialização. Agora, presenciamos uma nova dimensão das distâncias, onde o fator tempo pode ser entäo o elemento determinante: as trocas, a produção, o próprio consumo trazem em seu interior a necessidade de serem movidos sob o signo a velocidade; ocorrendo assim redefiniçäo das relações sócioespaciais, em função do tempo dos deslocamentos. Desta forma, outra hierarquia e vinculação entre os centros urbanos do pals ficou delineada sob o impacto das inovações deste novo periodo. A proliferação de novos centros urbanos, e muitos assumindo a função de pólo regional, delinearam uma nova expressão à hierarquia urbana e uma especialização da atividade produtiva dentro das regiões. Podemos observar que as diferentes partes do território, tendem na atualidade a se especializar, ou mesmo como afirma SANTOS (1988a, p. 50), “....assistimos à espacialização funcional das áreas e lugares, o que leva à intensificação do movimento e à possibilidade crescente das trocas". $E$ ainda acrescenta $O$ autor, em função destas novas condições, crescem não apenas as grandes cidades, mas também as cidades médias.

Mediante tais inovações, as distâncias podem ser vencidas com maior facilidade assim como as atividades podem ser descentralizadas, repercutindo na especialização e complementariedade entre as regiōes, antes dispersas pelo território. Se atualmente, no Sudoeste do território nacional, podemos notar uma concentração de recursos e da produção em algumas grandes metrópoles, podemos também apontar para a existência de uma dispersão, onde se destacam as capitais regionais. Como aponta SANTOS (1988b), ...."encontramos pedaços e ressonâncias da metrópole por todo o território".

LINARDI, M.C.N. Thinking about the Contemporary City. Semina: Ci. Soc./Hum., Londrina, v. 15, n. 3, p. 239-245, Sept. 1994.

ABSTRACT: Our purpose here is to identify some topics concerned to the comprehension of the contemporary city. Therefore, through notions of time, velocity, obsolescence of places and things, innovation of science and technology we are able to approach different levels that seem to contribute to a redefinition of social-spatial relations present in the city nowadays. In methodological terms we can emphasize the importance of adopting, as a starting point, the historical knowledge considered here as the comprehension of reality itself. We believe as well that this is the mechanism that leads to the renewal of theory. The present modernity was stablished as a historical mark when the contemporary city was approached. The latter is characterized not only by the intense proliferation of objects, their abundance, but also by the rapidity in which these objects are processed and by the technical sophistication in which they are produced. We search through our analysis to observe how velocity and new rhythms, characteristic of the present moment remodel the urban surroundings, which tend to become obsolete in shorter intervals of time.

KEY-WORDS: Contemporary City, Time, Velocity, Obsolescence, Present Modernity.

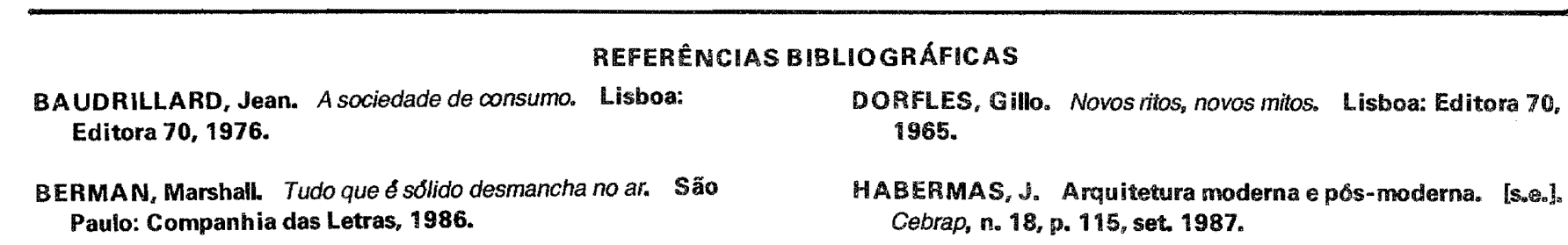

Semina Ci. Soc./Hum., v. 15, n. 3, p. 239-245 


\title{
DEPENDÊNCIA E DESENVOLVIMENTO NA AMÉRICA LATINA: O PAPEL DOS ESTADOS NACIONAIS NA NOVA ORDEM MUNDIAL
}

\author{
RONALDO BALTAR 1
}

BALTAR, $R$. Dependência e Desenvolvimento na América Latina: o papel dos Estados nacionais na nova ordem

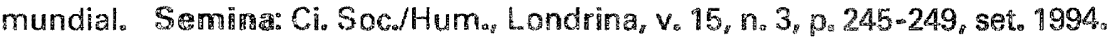

AESUHO: A questão básica proposta neste texto visa discutir a relação entro Estado e economia da perspectiva da internacionalizaçâo dos mercados e do capitai, partindo da premissa de que a compreensão do desenvolvimento do capitalismo moderno estå alëm dos estudos que possuem como objeto os Estados nacionais isoladamente. As questóes referentes à compreensão das transformaçes politicas na América Latina passam a requerer análises integradas, de forma a que seja possivel dimensionar o papei das crises econömicas a das mudanças de regimes politicos na especificidade do processo de desenvolvimento capitalista dos palses labinoamericanos.

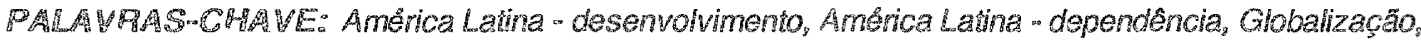
Mercado - intenacionalização

\section{- MTRODUGRO}

A questäo básica proposta neste texto visa uma discussão, ainda inicial, sobre a relaçăo entre Estado e economia na América Latina da perspectiva da intemaciona. lizaçäo dos mercados e do capital, partindo da premissa de que a compreensão do desenvolvimento do capitalismo moderno está além dos estudos que possuem como objeto os Estados nacionais isoladamente. As questöes referentes à compreensão das transformações politicas na América Latina, sobretudo, passam a requerer anålises integradas, de forma que seja possivel dimensionar o papel das crises económicas a das mudanças de regimes politicos na especificidade do processo de desenvolvimento capitalista dos paises latino-americanos.

O centro deste tipo de abordagem está na análise dos liames entre ordem polf́tica democrática, autoritarismo e crise econômica. Difere, no entanto, dos estudos que procuraram responder a esta questão a partir de instrumentos analiticos estritamente institucionais, tais $\mathrm{CO}$. mo análises eleitorais, estudos sobre o discurso e o com- portamento de grupos políticos e a comparaça entre tio pos de instituiçóes politicas de paises diferentes em siruações paralelas (democratizaçäo, etco) Também difere da anålise marxista ontodoxa, na medida em que esta tende a subdimensionar o papel da esfera politica na conforma. çäo do processo de desenvolvimento econômico, atribuindo uma relaçäo de reciprocidade mecánica entre in. teresses politicos e interesses econômicos, ambos englo. bados ao conceito de interesses de classe. Diverge tam be̊m da análise econômica pura, uma vez que o instrumental analítico da economia prende-se fundamentalmente na reflexão dedutiva por comparação de modelos. Diante da atual diversidade de caminhos apresentados pelo processo de expansäo do capitalismo mundial, os modelos tradicionais de interpretação da dinâmica capitalista, amparados em paradigmas históricos como a revolução industrial inglesa, por exemplo, nảo conseguem reunir elementos suficientes para a compreensão das atuais transformaçōes vividas pelas sociedades ociden. tais.

O caminho para tornar esta reflexão possivel segue

1 - Departamento de Ciências Sociais da Universidade Estadual de Londrina, Caixa Postal 6001, Londrina, Paraná, Brasil, CEP 86051-970. 